\title{
Expression of prolactin mRNA and of prolactin-like proteins in endothelial cells: evidence for autocrine effects
}

\author{
C Clapp, F J López-Gómez, G Nava, A Corbacho, L Torner, \\ Y Macotela, Z Dueñas, A Ochoa, G Noris, E Acosta, E Garay and \\ G Martínez de la Escalera \\ Centro de Neurobiología, Universidad Nacional Autónoma de México, 76001 Querétaro, Qro, México \\ (Requests for offprints should be addressed to Dr Carmen Clapp, Centro de Neurobiología, Universidad Nacional Autónoma de México, \\ Apartado Postal 1-1141, 76001 Querétaro, Qro, Mexico)
}

\begin{abstract}
Formation of new capillary blood vessels, termed angiogenesis, is essential for the growth and development of tissues and underlies a variety of diseases including tumor growth. Members of the prolactin hormonal family bind to endothelial cell receptors and have direct effects on cell proliferation, migration and tube formation. Because many angiogenic and antiangiogenic factors are produced by endothelial cells, we investigated whether endothelial cells expressed the prolactin gene. Here we show that bovine brain capillary endothelial cells (BBCEC) in culture express the full-length prolactin messenger RNA, in addition to a novel prolactin transcript, lacking the third exon of the gene. In addition cultures of BBCEC synthesize and secrete prolactin-like immunoreactive proteins with apparent molecular masses of 23, 21 and $14 \mathrm{kDa}$. The
\end{abstract}

prolactin-like nature of these proteins is supported by the observation that $\mathrm{Nb} 2$-cells, a prolactin-responsive cell line, were stimulated to proliferate when co-cultured with endothelial cells and this stimulation was neutralized with prolactin-directed antibodies. Finally, consistent with a possible autocrine effect of endothelial-derived prolactins, polyclonal and monoclonal prolactin antibodies specifically inhibited basal and basic fibroblast growth-factorstimulated growth of endothelial cells. Taken together, the present findings support the hypothesis of the prolactin gene being expressed in endothelial cells as proteins that could act in an autocrine fashion to regulate cell proliferation.

Journal of Endocrinology (1998) 158, 137-144

\section{Introduction}

Angiogenesis is essential for the growth, development and repair of tissues. In the adult mammal, however, angiogenesis is rare. When it occurs, during wound healing or in response to ovulation, it is tightly controlled and delimited (Folkman \& Klagsbrun 1987, Polverini 1995). Failure of this control is associated with a variety of diseases dominated by pathologic neovascularization, including neoplasia, diabetic retinopathy, rheumatoid arthritis, psoriasis and arteriosclerosis (Folkman \& Klagsbrun 1987, Polverini 1995).

Positive and negative signals regulating angiogenesis act on endothelial cells to stimulate or inhibit their migration, proliferation or association into capillary tubes. Several stimulators and inhibitors of endothelial cell function have been described, most of which are produced by cells within the vicinity of the capillary network (Folkman \& Klagsbrun 1987, Klagsbrun \& D’Amore 1991, Auerbach \& Auerbach 1994, Battegay 1995). Moreover endothelial cells produce and respond to their own angiogenic or antiangiogenic factors (autocrine regulation). Endothelial peptides with autocrine effects include basic fibroblast growth factor (bFGF), plateletderived growth factor (PDGF), vascular endothelial growth factor (VEGF) and thrombospondin (McPherson et al. 1981, Schweigerer et al. 1987, Koyama et al. 1994, Nomura et al. 1995). Autocrine regulation could help explain the local differences of cell growth and differentiation that must be established in a capillary microenvironment and that are involved, for example, in the selection of a single endothelial cell to initiate a capillary network.

Prolactin (PRL) gene is expressed in the pituitary gland, and at several other sites including the central nervous system and the immune system (Sinha 1995, Ben-Jonathan et al. 1996). Products of this gene function as hormones and cytokines regulating reproductive and immunological functions, fluid balance, cellular growth and differentiation (Nicoll 1980, Loretz \& Bern 1982, Russell 1989, Kelly et al. 1991). In addition, members of the PRL family have been implicated recently as potential 
regulators of angiogenesis. Fragments of PRL of 16 and $14 \mathrm{kDa}$ bind to endothelial cell receptors and inhibit endothelial cell proliferation and tube formation (Clapp \& Weiner 1992, Ferrara et al. 1991, Clapp et al. 1993, 1994). Likewise, the $16 \mathrm{kDa}$ amino-terminal fragment of PRL inhibits the in vivo development of the microvasculature of the chick chorioallantoic membrane (Clapp et al. 1993). Furthermore, two PRL-related proteins, proliferin and proliferin-related protein, were shown to stimulate and inhibit endothelial cell migration respectively, and to affect angiogenesis in vivo (Jackson et al. 1994). Here, we have investigated the hypothesis that the PRL gene could be expressed in endothelial cells, where its products may function as autocrine factors in the regulation of angiogenesis.

\section{Materials and Methods}

\section{$P R L$ and antibodies}

Bovine PRL and ovine PRL (BIO grade) and bovine PRL antiserum (RIA grade) were donated by the National Hormone and Pituitary Program (NHPP, Bethesda, MD, USA). The specificity of the NHPP PRL antiserum has been well characterized as it forms part of the kit distributed for RIA determinations of bPRL. Antisera were also raised locally in rabbits by immunization with the NHPP bovine PRL or ovine PRL. Specificity for bovine PRL of the locally raised antisera was assessed by RIA. At $1: 50000$ dilution, both antisera reacted with increasing concentrations of bovine PRL, whereas crossreactivity with bovine FSH or bovine $\mathrm{LH}$ was less than $0 \cdot 1 \%$. Bovine PRL monoclonal antibody (5G2) known to crossreact with a specific region of the amino-terminal disulfide loop of bovine PRL (Scammell et al. 1992) was kindly provided by J Scammell (University of South Alabama, Mobile, AL, USA). All antibodies were preservative-free.

\section{Endothelial cell culture}

Bovine brain capillary endothelial cells (BBCEC) were isolated as described elsewhere (Gospodarowicz et al. 1986), grown and serially passaged in BBCEC culture medium (low-glucose Dulbecco's modified Eagle's medium (DMEM, Gibco BRL, Gaithersburg, MD, USA) supplemented with $10 \%$ calf serum, $2 \mathrm{mM}$ glutamine, and penicillin/streptomycin $(50 \mathrm{U} / \mathrm{ml}))$ as previously reported (Ferrara et al. 1991, Clapp et al. 1993). Serum was not heat-inactivated. bFGF (1 ng/ml; Gibco BRL) was added to the cultures every other day and the cells were used between passages 5 and 12. Endothelial cells were characterized by their nonoverlapping cobblestone morphology and by the positive immunofluorescence for Von Willebrand factor in more than $95 \%$ of cells in the culture (Gerritsen et al. 1988).
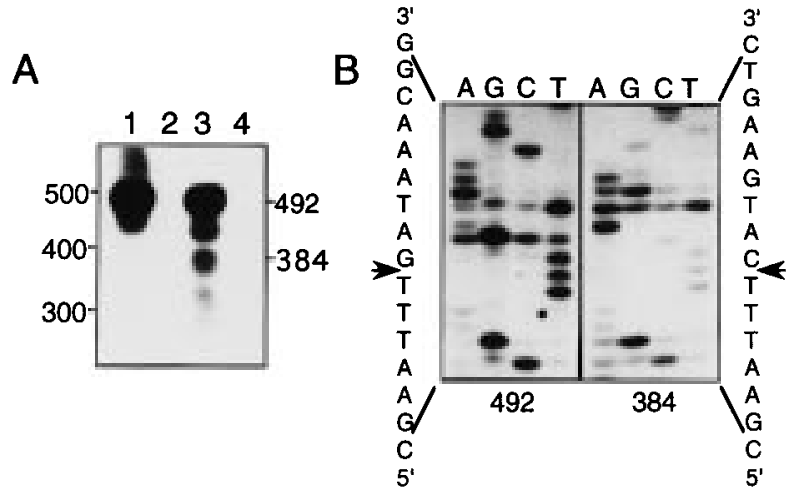

Figure 1 Identification of PRL mRNAs in BBCEC. (A) Southern blot analysis of PCR from reverse-transcribed total RNA from bovine anterior pituitary (lane 1 ) or BBCEC (lanes 2-4), amplified with primers bPRL-A and bPRL-2 without (lane 2) or with RT (lanes 3 and 4), and hybridized with a bovine PRL CDNA probe. Lane 4, negative control excluding RNA. (B) Sequencing gel of the 492and the 384-bp RT-PCR products from BBCEC at the downstream boundary of exon 2 (arrows). The 492-bp product has the sequence of the cloned bPRL cDNA, in which exon 2 is followed by exon 3 (Truong et al. 1984). In the 384-bp product, exon 2 is followed by exon 4 , denoting the loss of exon 3 of bPRL cDNA.

\section{Reverse transcriptase-polymerase chain reaction (RT-PCR)}

Total RNA from semiconfluent BBCEC was isolated and RT-PCR performed essentially as described previously (Clapp et al. 1994), using 36 cycles and an annealing temperature of $55^{\circ} \mathrm{C}$. Two primers complementary to bovine PRL cDNA were synthesized: forward primer bPRL-A (5'-GGGCAGTCATGGTGTCCCACTA-3') from exon 2 and downstream primer bPRL-2 (5'AAGTGTCAATCTTGCTTGAATC-3') from exon 5 (Fig. 1). RT-PCR products were identified by Southern blot using a homologous probe (bovine PRL cDNA, generously supplied by $\mathrm{R}$ Maurer, Oregon Health Sciences University, Portland, OR, USA) and performed as previously reported (Clapp et al. 1994). PCR transcripts were sequenced by the dideoxy method (Sanger et al. 1977) using the AmpliCycle kit (Perkin Elmer, Branchburg, NJ, USA) and $\alpha\left[{ }^{32} \mathrm{P}\right] \mathrm{dATP}$ (Dupont Co., Wilmington, DE, USA). The sequencing reactions were performed according to the manufacturer's instructions. Aliquots of the sequencing reactions were run on $6 \%$ acrylamide gels, vacuum dried, and autoradiographed for at least $18 \mathrm{~h}$.

Metabolic labeling and immunoprecipitation of de novo synthesized proteins

Semiconfluent BBCEC were metabolically labeled for $7 \mathrm{~h}$ with $\left[{ }^{35} \mathrm{~S}\right]$-cysteine and $\left[{ }^{35} \mathrm{~S}\right]$-methionine $(100 \mu \mathrm{Ci} / \mathrm{ml}$; Dupont Co.) in $0.2 \mathrm{mg} / \mathrm{ml} \mathrm{BSA}$, serum-free, low-glucose DMEM and lysed in $1 \%$ NP-40, $0.1 \%$ SDS, $50 \mathrm{mM}$ Tris, $150 \mathrm{mM} \mathrm{NaCl}, 1 \mu \mathrm{g} / \mathrm{ml}$ aprotinin and $100 \mu \mathrm{g} / \mathrm{ml}$ 
phenylmethylsulfonyl fluoride. BBCEC lysates and concentrated (4X; Centricon 3, Amicon, Beverly, MA, USA) culture media, were incubated overnight with a $1: 500$ dilution of bovine PRL antiserum (NHPP) or normal rabbit serum (NRS) followed by a 1-h incubation with protein A-Sepharose beads (Sigma) as described elsewhere (Sambrook et al. 1989). NRS was used for preclearing. Proteins were eluted from the Sepharose beads by boiling in electrophoresis sample buffer $(0.4 \mathrm{~g}$ SDS, $4 \mathrm{ml}$ $\beta$-mercaptoethanol, $2 \mathrm{ml}$ glycerol, $1 \mathrm{mg}$ bromophenol blue, $10 \mathrm{ml}$ water) and resolved in an SDS slab gel $(15 \%$ acrylamide/bisacrylamide). Gels were fixed, soaked in Enhance (Dupont Co.), dried and autoradiographed.

\section{$\mathrm{Nb} 2$ cell growth}

$\mathrm{Nb} 2$ cells, a PRL-responsive rat lymphoma cell line (kindly provided by $\mathrm{P}$ Gout, British Columbia Cancer Agency, Vancouver, BC, Canada), were grown in suspension in high-glucose DMEM containing $2 \beta$ mercaptoethanol $\left(10^{-4} \mathrm{M}\right)$ and supplemented with $10 \%$ horse serum, $10 \%$ fetal bovine serum and antibiotics as described by Tanaka et al. (1980). Sera were not heatinactivated. For individual experiments, $\mathrm{Nb} 2$ cells $\left(2.5 \times 10^{4}\right.$ cells $/ 15-\mathrm{mm}$ well $)$ were co-cultured with BBCEC previously attached to the wells at different $(0 \cdot 625$, 1.25 or $2.5 \times 10^{5}$ ) cellular densities, in the above incubation medium but without fetal calf serum. After $60 \mathrm{~h}$, $\left[{ }^{3} \mathrm{H}\right]$ thymidine was added to co-cultures for 4 or $12 \mathrm{~h}$. Because $\mathrm{Nb} 2$ cells grow in suspension, $\left[{ }^{3} \mathrm{H}\right]$ thymidine incorporation into $\mathrm{Nb} 2$ cells was assayed in co-cultures supernates after collecting the cells by centrifugation. Values were corrected by subtracting the c.p.m. present in supernates of BBCEC cultured in the absence of $\mathrm{Nb} 2$ cells. $\left[{ }^{3} \mathrm{H}\right]$ Thymidine incorporation was assayed essentially as previously described (Ferrara et al. 1991). Co-cultures were carried out in the absence or presence of a $1: 500$ dilution of bovine PRL antisera (NHPP) or locally produced anti-bovine PRL or anti-ovine PRL antisera or NRS.

\section{Endothelial cell growth}

To determine cell proliferation, BBCEC were plated $\left(10^{4}\right.$ cells/35-mm well or $2.5 \times 10^{3}$ cells/15-mm well) and

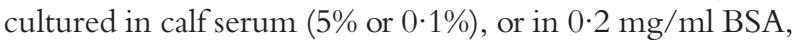
serum-free, low-glucose DMEM. Incubations were for $60 \mathrm{~h}$ with bFGF and antibodies added twice, once at the time of seeding the cells, and once again, $48 \mathrm{~h}$ later. At the end of incubations the number of viable cells was estimated by the dye exclusion method (Harlow \& Lane 1988) and cell proliferation assayed either by cell number (hemocytometer) or by measuring $\left[{ }^{3} \mathrm{H}\right]$ thymidine incorporation into cells. BBCEC were cultured in the absence or presence of $\mathrm{bFGF}(1 \mathrm{ng} / \mathrm{ml})$ alone or together with different concentrations of bovine PRL antiserum
(NHPP), bovine PRL monoclonal antibody, NRS or preimmune mouse IgGs (Sigma Chemical Co., St Louis, MO, USA). For neutralization experiments, cells were cultured with bFGF and PRL antibodies in combination with bovine PRL (100 nM). Specificity to endothelial cells was analyzed by testing the effect of PRL monoclonal antibody on NIH/3T3 cells. NIH/3T3 cells obtained from American Type Culture Collection (Rockville, MD, USA) were maintained in 5\% calf serum, BBCEC culture medium and the mitogenic effects of bFGF alone or in combination with the PRL monoclonal antibody were analyzed as described for BBCEC. Detection and quantitation of endotoxin in all PRL antibodies was determined by the Limulus amebocyte lysate assay using the TOXATE kit (Sigma) as previously reported (Clapp et al. 1993).

\section{Statistical analysis}

The data were analyzed for statistical significance by Student's $t$-test. Results are expressed as the means \pm standard error of the mean of triplicate determinations. Results were replicated in three or more independent experiments.

\section{Results}

Identification of PRL gene transcripts by RT-PCR and sequence analysis

Total RNA from BBCEC was reverse-transcribed and amplified by PCR using primers with annealing sites within exons 2 and 5 of the bovine PRL cDNA. Southern blot analysis showed a PCR product of $492 \mathrm{bp}$, which corresponded in size to that amplified from bovine anterior pituitary RNA and consistent with the predicted size for the cloned full-length 23-kDa PRL mRNA (Fig. 1A). Smaller size PCR fragments were also amplified from BBCEC: the two most abundant were of about 430 and $384 \mathrm{bp}$. No positive signal was detected in the absence of reverse transcriptase or in the negative control without RNA (Fig. 1A). Similarly, no signal was observed in NIH/3T3 fibroblasts (not shown). The amplified 492-bp product showed identical sequence homology with bovine pituitary PRL throughout an analyzed region of $181 \mathrm{bp}$ comprising codons encoding for amino acids 31-91 (Fig. 1B). Direct sequencing of the 384-bp PCR product showed total sequence identity with pituitary PRL over an analyzed region of $157 \mathrm{bp}$, corresponding to codons encoding for amino acids 31-40 and 77-119. An entire region of $108 \mathrm{bp}$ encoding for amino acids $41-76$ was missing in this transcript (Fig. 1B). The sequence of this smaller transcript showed third-base substitutions at codons 95 (cytosine instead of guanine) and 103 (guanine instead of adenine) with respect to a reported pituitary 


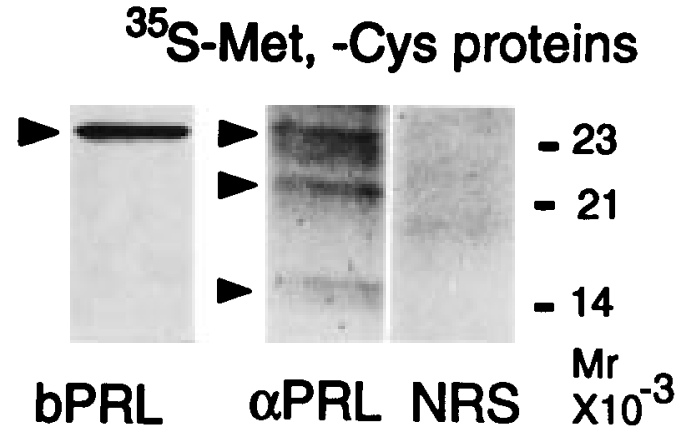

Figure 2 Metabolically labeled BBCEC culture media immunoprecipitated with NHPP bovine PRL antiserum ( $\alpha b P R L)$ or normal rabbit serum (NRS). PRL-like proteins and the $\left.{ }^{125} \mathrm{I}\right]$-labeled bovine PRL (bPRL) are indicated (arrows), in addition to their relative molecular mass $(\mathrm{Mr})$.

bovine PRL cDNA (pBPRL72) (Sasavage et al. 1982). However, both substitutions have been reported for another PRL cDNA clone (pBPRL4) also obtained from the bovine pituitary (Sasavage et al. 1982). The 430-bp PCR product was not sequenced.

\section{Detection of PRL-like proteins in endothelial cells}

Metabolic labeling and immunoprecipitation To assay for the translational products of PRL transcripts in endothelial cells, protein synthesis was metabolically labeled with $\left[{ }^{35} \mathrm{~S}\right]$-cysteine and $\left[{ }^{35} \mathrm{~S}\right]$-methionine in BBCEC and the $\left[{ }^{35} \mathrm{~S}\right]$-labeled PRL-like proteins immunoprecipitated with bovine PRL antiserum (NHPP). PRL antiserum, but not pre-immune serum, precipitated $\left[{ }^{35} \mathrm{~S}\right]-$ PRL-like proteins with apparent molecular masses of 23 , 21 and $14 \mathrm{kDa}$ in BBCEC-conditioned media (Fig. 2). Also, a labeled, diffuse PRL-like protein band was detected within the $22-\mathrm{kD}$ a region. Sizes were estimated by comigration with $23-\mathrm{kDa}$ bovine PRL and molecular mass markers. No labeled PRL-like proteins were detected in BBCEC lysates (not shown).

Stimulation of $\mathbf{N b} 2$ cell growth To analyze the PRLlike nature of endothelial proteins, BBCEC were seeded at different densities and co-cultured with PRL-responsive $\mathrm{Nb} 2$ rat lymphoma cells. BBCEC significantly stimulated the proliferation of $\mathrm{Nb} 2$ cells (Figs 3 and 4). The greatest level of activity in the conditioned media of BBCEC $-\mathrm{Nb} 2$ co-cultures was equivalent to $30 \mathrm{pg} / \mathrm{ml}$ pituitary PRL as estimated by serial dose-response effects of bovine PRL standard (Fig. 3). Stimulation of $\mathrm{Nb} 2$ cell growth by endothelial cells and bovine PRL standard was abolished in the presence of the NHPP bovine PRL antiserum, but not affected by preimmune serum (Fig. 3). Moreover, in experiments depicted in Fig. 4, in which greater values of $\left[{ }^{3} \mathrm{H}\right]$ thymidine incorporation followed a longer

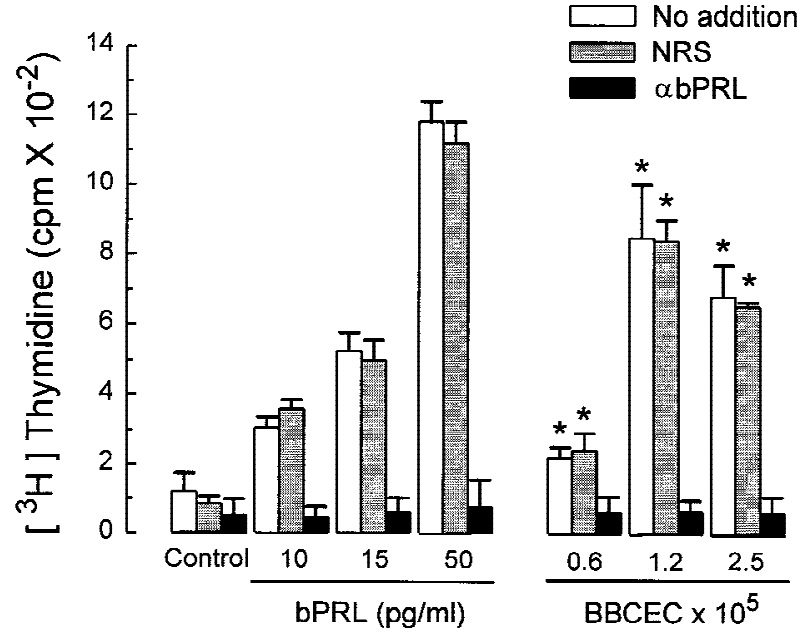

Figure $3\left[{ }^{3} \mathrm{H}\right]$ Thymidine incorporation into $\mathrm{Nb} 2$ cells cultured in the absence (control) or presence of increasing concentrations of bovine PRL (bPRL) or co-cultured with BBCEC at various cellular densities in the absence (no addition) or presence of normal rabbit serum (NRS), or of NHPP bovine PRL antiserum ( $\alpha \mathrm{bPRL}$ ). $\left[{ }^{3} \mathrm{H}\right]$ Thymidine was added to all cultures for $4 \mathrm{~h} .{ }^{*} P<0 \cdot 05$ compared with controls.

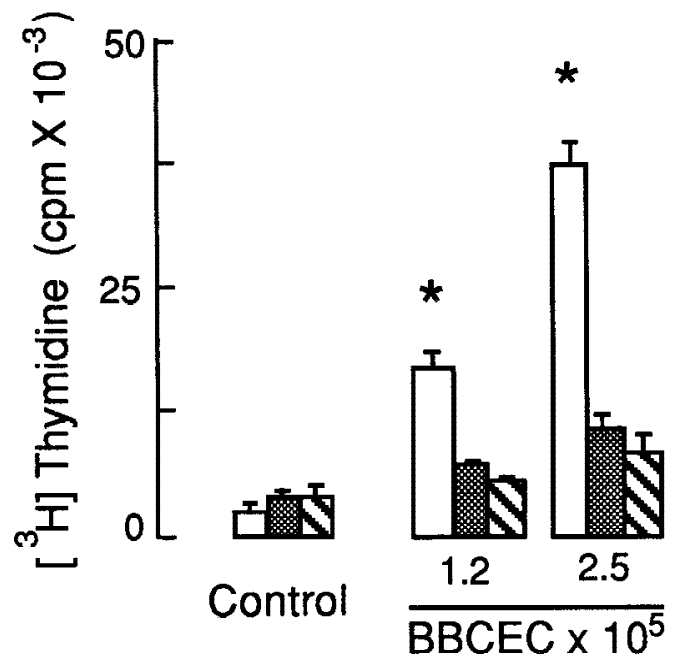

Figure $4\left[{ }^{3} \mathrm{H}\right]$ Thymidine incorporation into Nb2 cells cultured in the absence (control) or presence of BBCEC at two cellular densities without further treatment (white bars) or after being cultured with locally produced antisera against bovine PRL (gray bars) or ovine PRL (hatched bars). $\left[{ }^{3} \mathrm{H}\right]$ Thymidine was added to all cultures for 12 h. ${ }^{*} P<0 \cdot 05$ compared with controls.

incubation with the tracer (12 compared with $4 \mathrm{~h}$, for experiments shown in Fig. 3), the stimulation of $\mathrm{Nb} 2$ proliferation induced by endothelial cells was bocked by locally raised bovine PRL and ovine PRL antisera. Both of these antisera abolished the $\mathrm{Nb} 2$ proliferative effect of increasing concentrations of bPRL (Fig. 5A) with this inhibition being dependent on the antisera dilution (Fig. 5B). 


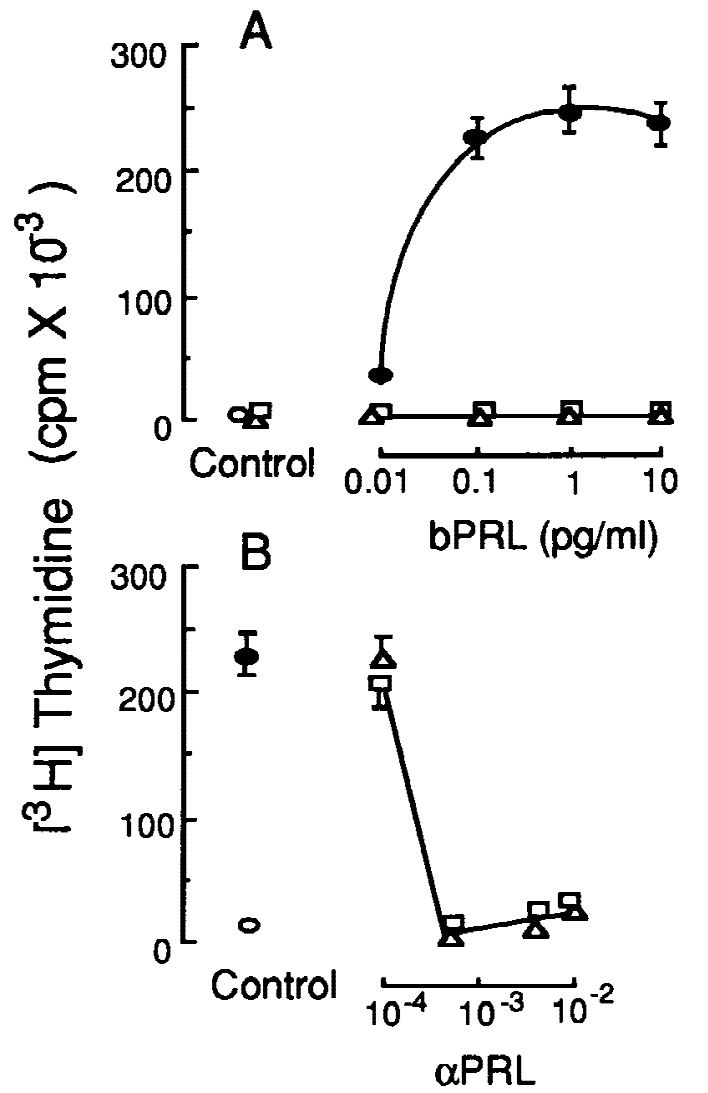

Figure 5 Blockage of PRL-induced stimulation of $\left[{ }^{3} \mathrm{H}\right]$ thymidine incorporation into $\mathrm{Nb} 2$ cells by locally produced bovine or ovine PRL antisera. (A) Nb2 cells were cultured in the absence of PRL (controls) or the presence of increasing concentrations of bovine PRL (bPRL) alone $(\mathbf{O})$ or together with a $1: 500$ dilution of locally produced anti-bovine PRL $(\square)$ or anti-ovine PRL $(\triangle)$ antisera. (B) $\mathrm{Nb} 2$ cells were cultured in the absence $(\bigcirc)$ or presence of bovine PRL (100 pg) alone $(\mathbf{O})$ or together with increasing concentrations of locally produced anti-PRL antisera ( $\alpha \mathrm{PRL}$ : anti-bovine PRL, $\square$; anti-ovine PRL, $\triangle$ ). $\left[{ }^{3} \mathrm{H}\right]$ Thymidine was added to all cultures for $12 \mathrm{~h}$.

\section{Effect of anti-PRL antibodies on endothelial cell growth}

To investigate a possible effect of endothelial PRLs on endothelial cell growth, we determined whether proliferation of BBCEC in culture could be affected by PRLdirected antibodies, capable of neutralizing the action of endogenous PRLs. Antiserum to bovine PRL inhibited both basal and bFGF-stimulated proliferation of BBCEC as determined directly by cell numbers (Fig. 6A), and by $\left[{ }^{3} \mathrm{H}\right]$ thymidine incorporation into DNA (Fig. 6B). Inhibition of both parameters was dose-dependent. After incubation with antiserum $(1: 1000)$, the number of BBCEC was similar to the number of cells seeded, which indicated that, at this antiserum dilution, there was a total blockage of endothelial cell proliferation (Fig. 6A). In addition, bFGF-stimulated $\left[{ }^{3} \mathrm{H}\right]$ thymidine incorporation

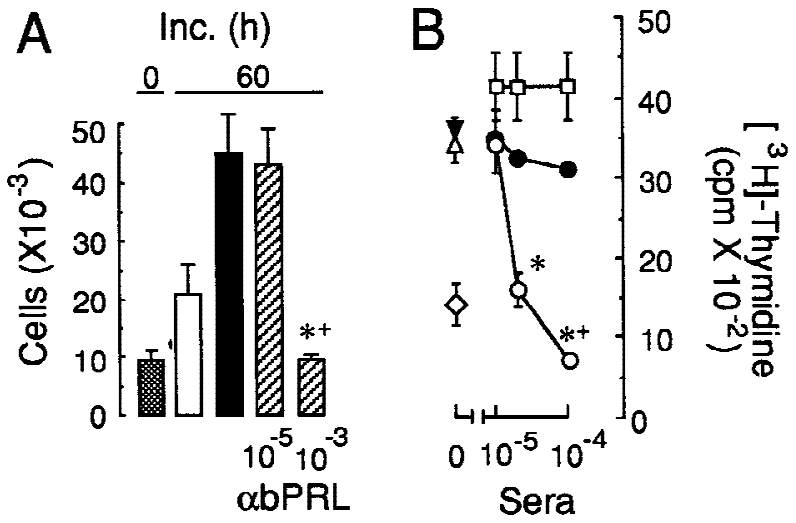

Figure 6 Effect of anti-bovine PRL antibodies on BBCEC proliferation. (A) Effect of NHPP bovine PRL-antiserum ( $\alpha \mathrm{bPRL}$ ) on number of BBCEC. Cells were seeded (stippled bar) and cultured (Inc.) for $60 \mathrm{~h}$ in $5 \%$ calf serum in the absence (white bar) or presence of bFGF $(1 \mathrm{ng} / \mathrm{ml})$ alone (black bar), or together with $10^{-5}$ or $10^{-3}$ NHPP abPRL (hatched bars). (B) Dose-dependent effect of NHPP $\alpha$ bPRL on $\left[{ }^{3} \mathrm{H}\right]$ thymidine incorporation into BBCEC. Cells were cultured in $0 \cdot 1 \%$ calf serum in the absence $(\diamond)$ or presence of bFGF $(1 \mathrm{ng} / \mathrm{ml})$ alone $(\boldsymbol{\nabla})$, or together with bPRL $(100 \mathrm{nM}, \triangle)$, NRS $(\square), \mathrm{NHPP} \alpha \mathrm{bPRL}(\bigcirc)$, or NHPP $\alpha b P R L$ in combination with bPRL $(100 \mathrm{nM}, \mathbf{0}) .{ }^{*} P<0.05$ compared with bFGF-treated control; ${ }^{+} P<0.05$ compared with bFGF-untreated control.

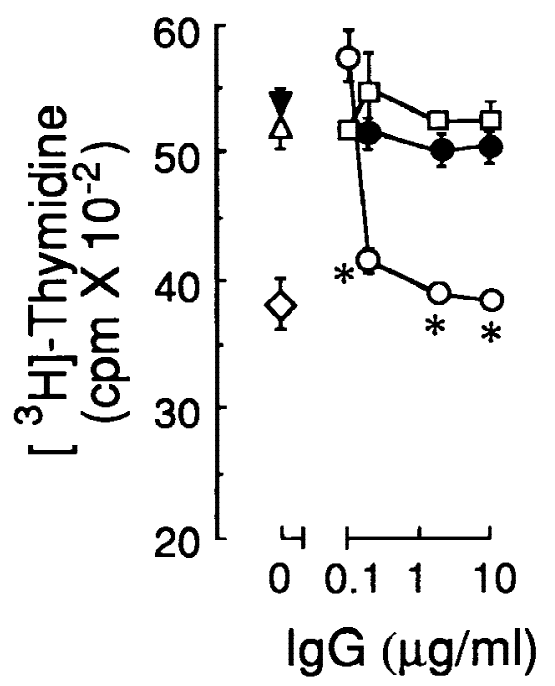

Figure 7 Dose-dependent effect of a bovine PRL monoclonal antibody (bPRL Mab) on $\left.{ }^{3} \mathrm{H}\right]$-thymidine incorporation into BBCEC. Cells were cultured in $0 \cdot 1 \%$ calf serum in the absence $(\diamond)$ or presence of bFGF $(1 \mathrm{ng} / \mathrm{ml})$ alone $(\boldsymbol{\nabla})$, or together with bovine PRL $(100 \mathrm{nM}, \triangle)$, preimmune mouse IgG $(\square)$, bPRL Mab $(\bigcirc)$, or bPRL Mab in combination with bPRL $(100 \mathrm{nM}, 0) .{ }^{*} P<0.05$ compared with bFGF-treated control.

into BBCEC was inhibited by a bovine PRL monoclonal antibody in a dose-dependent fashion (Fig. 7). The action of both polyclonal and monoclonal PRL antibodies was neutralyzed with exogenous PRL and no effect on BBCEC proliferation followed culture with NRS or 
preimmune IgGs (Figs 6B and 7). The inhibitory effect of PRL antibodies was independent of the presence of serum in the cultures, since it was observed in cells cultured in $5 \%$ calf serum (Fig. 6A), in cells cultured with $0 \cdot 1 \%$ calf serum (Figs. 6B and 7), and in cells cultured in defined medium in the absence of serum (data not shown). The bovine PRL monoclonal antibody did not modify basal or bFGF-stimulated $\left[{ }^{3} \mathrm{H}\right]$ thymidine incorporation into NIH3T3 cells (data not shown). Cell viability, determined by trypan blue exclusion, was not affected by PRL antibodies at the dilutions used (data not shown) and a $1: 100$ dilution of all PRL antibodies had undetectable levels of endotoxin $(<0.03 \mathrm{EU})$, arguing against a toxic action.

\section{Discussion}

The endothelium is the production site for several factors with the ability to stimulate or inhibit the formation of new blood vessels (McPherson et al. 1981, Schweigerer et al. 1987, Klagsbrun \& D'Amore 1991, Auerbach \& Auerbach 1994, Koyama et al. 1994, Nomura et al. 1995). Autocrine angiogenic and antiangiogenic factors provide an insight into the mechanisms by which endothelial cell growth is selectively supported or prohibited locally within a tissue microenvironment.

Recent work has implicated PRL-related proteins as potential regulators of angiogenesis (Ferrara et al. 1991, Clapp \& Weiner 1992, Clapp et al. 1993, 1994, Jackson et al. 1994). The present study extends and strengthens those discoveries by showing that PRLs may be produced by the endothelial cells themselves, and that they may constitute a novel group of autocrine regulators of angiogenesis. The current results are consistent with the expression of the PRL gene in endothelial cells and with PRL-related proteins acting in an autocrine manner to regulate endothelial cell proliferation.

Expression of the PRL gene in endothelial cells is indicated by RT-PCR-Southern blot and sequence analyses of total RNA from BBCEC. Specificity to endothelial cells is suggested by the lack of PRL gene PCR amplification signal in NIH/3T3 fibroblasts. A PCR product with the same size and sequence as that amplified from the pituitary gland corresponding to the full-length $23 \mathrm{kDa}$ PRL mRNA was identified in BBCEC. In addition, smaller PRL transcripts of 430 and $384 \mathrm{bp}$ were detected. The 384-bp transcript was found to be devoid of a 108-bp region comprising codons encoding for amino acids 41-76. This region corresponds to exon 3 in the human PRL gene and in the rat PRL gene (Gubbins et al. 1980, Truong et al. 1984). Although genomic sequence data for bovine PRL remain incomplete, the homology found among species strongly suggests that this small transcript could correspond to a novel PRL mRNA in which exon 2 is being spliced directly onto exon 4 without affecting the reading frame. This alternative splicing predicts a protein with a molecular mass of about $20 \mathrm{kDa}$. Although the full-length PRL mRNA is responsible for $23-\mathrm{kDa}$ PRL, the bulk hormone in most tissues of origin, the third-exon-deleted PRL transcript has not been found elsewhere in other PRL-producing tissues. This could imply that its expression, and perhaps the function of the protein encoded by it, may be endothelial-cell-specific.

Support for the translation of the PRL gene in endothelial cells is provided by metabolic labelingimmunoprecipitation studies. PRL-like antigens, with apparent molecular masses of 23, 21 and $14 \mathrm{kDa}$, were found to be synthesized and secreted into the culture medium of BBCEC. The sizes of the 23- and 21-kDa proteins paralleled those expected for the translational products of two of the PRL mRNAs detected in BBCEC - that is, the full-length PRL transcript and the thirdexon-deleted alternative spliced mRNA. In addition, a PRL-like protein of about $22 \mathrm{kDa}$ appears to have been detected that may correspond to the translational product of the 430-bp PRL transcript also found in BBCEC. Interestingly, the smaller, $14-\mathrm{kDa}$, protein has a size similar to that of a previously identified $14-\mathrm{kDa}$ fragment of PRL with antiangiogenic effects (Clapp et al. 1994). Although the final identification of these proteins remains to be determined, these results are consistent with PRLs being produced and secreted by endothelial cells.

Further support for the secretion of PRLs by endothelial cells resulted from co-culturing BBCEC with the pre-T rat lymphoma $\mathrm{Nb} 2$ cells. Mitogenesis of $\mathrm{Nb} 2$ cells is highly dependent on PRL-like factors (Shiu et al. 1983). BBCEC stimulated the proliferation of $\mathrm{Nb} 2$ cells with a potency directly related to endothelial cell number. The PRL-like nature of the stimulatory factor(s) is indicated by the fact that PRL-directed antibodies, able to block the stimulatory action of exogenous PRL, abolished the stimulation of $\mathrm{Nb} 2$ cell proliferation by endothelial cells.

It is clear that the level of PRL gene expression and of the PRL-like proteins in endothelial cells is low. Highly sensitive techniques (RT-PCR and radioactive metabolic labeling) are required for their detection, and picogram amounts of biologically active PRLs were measured. The observed low level of PRL expression may be of significant value. Sensitive techniques are a common requirement for the detection of locally acting factors, particularly when little is known about regulation of their expression. The mRNA of vascular endothelial cell growth factor (VEGF) is nondetectable by Northern blots in retinal cells grown under normal oxygen conditions, but easily detected after hypoxia (Shima et al. 1995). Low levels of PRL expression, requiring RT-PCR and metabolic labeling, have been reported in neurons and immune cells in which PRLs are known to function as autocrine paracrine regulatory factors (Ben-Jonathan et al. 1996, Yu-Lee 1997). 
In support of the assumption that the PRL level of expression in endothelial cells is of significant value, polyclonal and monoclonal PRL antibodies inhibited the proliferation of BBCEC in culture. The action of PRL antibodies was found to be specific because their effect was neutralized with exogenous PRL, and no action followed culture of the cells with preimmune antibodies. Furthermore, in support of endothelial cells as the source of these PRL-like proteins, the action of PRL antibodies was not dependent on the presence of serum in the culture medium. The fact that PRL antibodies inhibited the growth of endothelial cells is consistent with the possibility of endothelial-derived PRLs acting in an autocrine manner to stimulate cell proliferation.

The conclusion of PRLs being angiogenic is surprising, given that the proteolytic fragments of PRL inhibit (rather than stimulate) endothelial cell proliferation, and fulllength PRL neither binds nor affects endothelial cells (Ferrara et al. 1991, Clapp \& Weiner 1992, Clapp et al. 1993, 1994). In contrast, PRLs with opposite effects on angiogenesis may not be unlikely. Two PRL-related proteins, proliferin and proliferin-related protein, have been shown to stimulate and inhibit respectively endothelial cell migration (Jackson et al. 1994). The conclusive identification of angiogenic PRL-like molecules awaits their purification and subsequent characterization. Nevertheless, alternative explanations to a PRL stimulatory action may also be feasible. For example, the inhibitory action of PRL antibodies could have been the result of an anti-proliferative signal, rather than of a block of a proliferative signal; addition of the antibodies to the cell cultures could have more effectively crosslinked an anti-angiogenic PRL fragment bound at the cell surface, thereby triggering an anti-proliferative signal. Comparisons of the effects given by bivalent and monovalent antibodies should provide valuable insights on this latter possibility.

No conclusions can be drawn on which one of the endothelial-derived PRLs (23-, 21- and 14-kDa isoforms) could be responsible for the proposed autocrine effects on endothelial cell proliferation. It is likely, however, that the active PRL(s) may differ structurally from pituitary 23-kDa PRL. Full-length 23-kDa pituitary prolactin was found to be inactive on endothelial cells (Ferrara et al. 1991, Clapp et al. 1993, 1994), a result confirmed recently using a wide range of doses of $23-\mathrm{kDa}$ PRL alone or in combination with bFGF (C Clapp, unpublished observations). Furthermore, the receptors for pituitary $23-\mathrm{kDa}$ PRL appear to be absent from endothelial cells. Fulllength pituitary PRL shows no binding affinity for endothelial cell membranes (Clapp \& Weiner 1992) and RT-PCR experiments with PRL-receptor-specific primers have failed to detect the cloned PRL receptors in endothelial cells (C Clapp and P A Kelly, unpublished observations). In contrast, endothelial cells do express a novel receptor for PRL molecules that does not bind pituitary PRL. Ligand binding and chemical crosslinking studies showed that $16-\mathrm{kDa}$ PRL, but not pituitary 23-kDa PRL, binds to high-affinity, saturable sites in endothelial cell membranes distinct in size from the cloned PRL receptors (Clapp \& Weiner 1992). A plausible hypothesis is that endothelial-derived PRLs, structurally different from pituitary 23-kDa PRL, may exert their autocrine effects through the activation of the new set of endothelial-specific receptors.

On the basis of this hypothesis, likely candidates for the active endothelial-derived PRLs are the 14-kDa PRL-like protein, as it has a size similar to that of PRL fragments that bind to endothelial cells and have effects on angiogenesis (Clapp \& Weiner 1992, Clapp et al. 1994), and the $21-\mathrm{kDa}$ protein, presumed to be the translational product of the third-exon-deleted PRL transcript. The amino acid sequence encoded by exon 3 is an important component of one of the two known binding domains of PRL to the cloned receptors, and its deletion is expected to generate a protein with reduced capacity to activate them (De Vos et al. 1992, Fuh et al. 1993, Goffin et al. 1995). Therefore, it is conceivable that the third-exon-spliced variant, if active, would operate through a new set of PRL receptors.

Identification of the molecular forms of PRLs produced by endothelial cells is of major importance for understanding the specific role and receptors involved in the regulation of endothelial cell function by this family of hormones and cytokines. Cloning and purification techniques involving specific antibodies are currently being undertaken.

\section{Acknowledgements}

We are indebted to Fernando López Barrera for his expert technical assistance. This work was supported in part by grants from the National University of Mexico (DGAPA IN201895), from the National Council of Science and Technology of Mexico (3662PN) and from the Howard Hughes Medical Institute (No. 75197-554801).

\section{References}

Auerbach W \& Auerbach R 1994 Angiogenesis inhibition: a review. Pharmacology and Therapeutics 63 265-311.

Battegay EJ 1995 Angiogenesis: mechanistic insights, neovascular diseases, and therapeutic prospects. Journal of Molecular Medicine $\mathbf{7 3}$ 333-346.

Ben-Jonathan N, Mershon JL, Allen Dl \& Steinmetz RW 1996 Extrapituitary prolactin: distribution, regulation, functions, and clinical aspects. Endocrine Review 17 639-669.

Clapp C \& Weiner RI 1992 A specific, high-affinity, saturable binding site for the 16-kiloDalton fragment of prolactin on capillary endothelial cells. Endocrinology 130 1380-1386.

Clapp C, Martial JA, Rentier-Delrue F, Guzman R \& Weiner RI 1993 The 16-kiloDalton N-terminal fragment of human prolactin is a potent inhibitor of angiogenesis. Endocrinology 133 1292-1299.

Clapp C, Torner L, Gutierrez-Ospina G, Alcántara E, López-Gómez FJ, Nagano M, Kelly PA, Mejía S, Morales MA \& 
Martínez de la Escalera G 1994 The prolactin gene is expressed in the hypothalamic-neurohypophyseal system and the protein is processed into a $14-\mathrm{kDa}$ fragment with activity like $16-\mathrm{kDa}$ prolactin. Proceedings of the National Academy of Sciences of the USA 91 10384-10388.

De Vos AM, Ultsch M. \& Kossiakoff AA 1992 Human growth hormone and extracellular domain of its receptor: crystal structure of the complex. Science 255 306-312.

Ferrara N, Clapp C \& Weiner RI 1991 The 16K fragment of prolactin specifically inhibits basal or fibroblast growth factor stimulated growth of capillary endothelial cells. Endocrinology 129 896-900.

Folkman J \& Klagsbrun M 1987 Angiogenic factors. Science 235 442-447.

Fuh G, Colosi P, Wood WI \& Wells JA 1993 Mechanism-based design of prolactin receptor antagonist. Journal of Biological Chemistry 268 5376-5381.

Gerritsen ME, Carley W \& Milici AJ 1988 Microvascular endothelial cells: isolation, identification and cultivation. In Advances in Cell Culture, vol 6, pp 35-67. Eds K Muramorsch \& K Satovol. New York: Academic Press Inc.

Goffin V, Martial JA \& Summers NL 1995 Use of a model to understand prolactin and growth hormone specificities. Protein Engineering 8 1215-1231.

Gospodarowicz D, Massoglia S, Cheng J \& Fujii DK 1986 Effect of fibroblast growth factor and lipoproteins on the proliferation of endothelial cells derived from bovine adrenal cortex, brain cortex and corpus luteum capillaries. Journal of Cellular Physiology 127 121-136.

Gubbins EJ, Maurer RA, Lagrimini M, Erwin CR \& Donelson JE 1980 Structure of the rat prolactin gene. Journal of Biological Chemistry 255 8655-8662.

Harlow E \& Lane D 1988 Antibodies, a Laboratory Manual, p 256. New York: Cold Spring Harbor Laboratory.

Jackson D, Volpert OV, Bouck NP \& Linzer DIH 1994 Stimulation and inhibition of angiogenesis by placental proliferin and proliferin-related protein. Science 266 1581-1584.

Kelly PA, Djiane J, Postel-Vinay MC \& Edery M 1991 The prolactin/growth hormone receptor family. Endocrine Review 12 235-251.

Klagsbrun M \& D’Amore PA 1991 Regulators of angiogenesis. Annual Review of Physiology 53 217-239.

Koyama N, Watanabe S, Tezuka M, Morisaki N, Saito Y \& Yoshida S 1994 Migratory and proliferative effect of plateletderived growth factor in rabbit retinal endothelial cells: evidence of an autocrine pathway of platelet-derived growth factor. Journal of Cellular Physiology 158 1-6.

Loretz CA \& Bern HA 1982 Prolactin and osmoregulation in vertebrates. Neuroendocrinology 35 292-304.

McPherson J, Sage H \& Bornstein P 1981 Isolation and characterization of glycoprotein secreted by aortic endothelial cells in culture. Apparent identity with platelet thrombospondin. Journal of Biological Chemistry 256 11330-11336.
Nicoll CS 1980 Ontogeny and evolution of prolactin's functions. FASEB Journal 39 2563-2566.

Nomura M, Yamaishi S, Harada S, Hayashi Y, Yamashima T, Yamashita J \& Yamamoto H 1995 Possible participation of autocrine and paracrine vascular endothelial growth factors in hypoxia-induced proliferation of endothelial cells and pericytes. Journal of Biological Chemistry $27028316-28324$.

Polverini PJ 1995 The pathophysiology of angiogenesis. Critical Reviews, Oral Biology and Medicine 6 230-247.

Russell DH 1989 New aspects of prolactin and immunity: a lymphocyte-derived prolactin like product and nuclear protein kinase C activation. Trends in Pharmacological Science 10 40-44.

Sambrook J, Fritsch EF \& Maniatis T 1989 Molecular Cloning: A Laboratory Manual. New York: Cold Spring Harbor Laboratory.

Sanger F, Nicklen S \& Coulson AR 1977 Sequencing with chain-terminating inhibitors. Proceedings of the National Academy of Sciences of the USA 74 5463-5467.

Sasavage NL, Nilson JH, Horowitz S \& Rottman FM 1982 Nucleotide sequence of bovine prolactin messenger RNA: evidence for sequence polymorphism. Journal of Biological Chemistry 257 678-681.

Scammell JG, Luck DN, Valentine DL \& Smith M 1992 Epitope mapping of monoclonal antibodies to bovine prolactin. American Journal of Physiology 263 E520-E525.

Schweigerer L, Neufeld G, Friedman J, Abraham JA, Fiddes JC \& Gospodarowicz D 1987 Capillary endothelial cells express basic fibroblast growth factor, a mitogen that promotes their own growth. Nature 325 257-259.

Shima DT, Adams AP, Ferrara N, Yeo K-T, Yeo T-K, Allende R, Folkman J \& D'Amore PA 1995 Hypoxic induction of endothelial cell growth factors in retinal cells: identification and characterization of vascular endothelial growth factor (VEGF) as the mitogen. Molecular Medicine 1 182-193.

Shiu RPC, Elsholtz HP, Tanaka T \& Friesen HG 1983 Receptormediated mitogenic action of prolactin in rat lymphoma cell line. Endocrinology 113 159-165.

Sinha YN 1995 Structural variants of prolactin: occurrence and physiological significance. Endocrine Review 16 354-369.

Tanaka T, Shiu RPC, Gout PW, Beer CT, Noble RL \& Friesen HG 1980 A new sensitive and specific bioassay for lactogenic hormones: measurement of prolactin and growth hormone in human serum. Journal of Clinical Endocrinology and Metabolism 51 1058-1063.

Truong AT, Duez C, Belayew A, Renard A, Pictet R, Bell GI \& Martial JA 1984 Isolation and characterization of the human prolactin gene. EMBO Journal 3 429-437.

Yu-Lee L 1997 Molecular actions of prolactin in the immune system. Proceedings of the Society for Experimental Biology and Medicine 215 $35-52$.

Received 24 November 1997

Revised manuscript received 2 December 1997 Accepted 10 March 1998 